
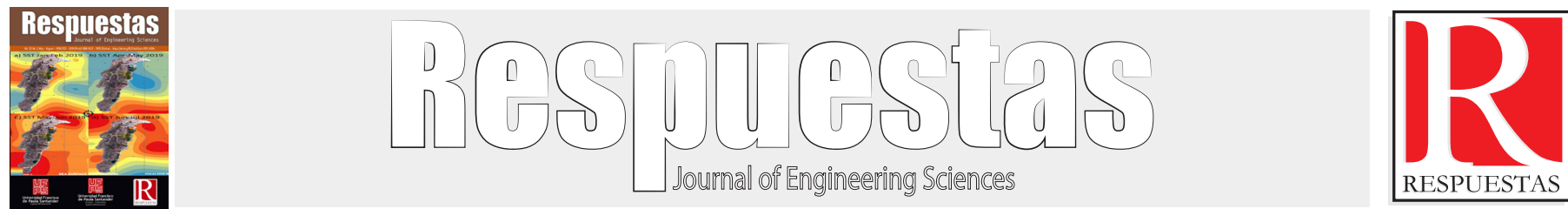

Original Article

https://doi.org/10.22463/0122820X.2405

\title{
Solar potential evaluation and political, economic and social analysis (pes) in the
} department cesar - colombia

Evaluación del potencial solar y analisis político, económico y social (pes) en el departamento del cesarcolombia

Marley Vanegas-Chamorro ${ }^{1 *}$, Danilo Hernández ${ }^{2}$, Eunice Villicaña-Ortiz ${ }^{3}$

${ }^{1 *}$ Doctor en Tecnología, diversificación, calidad y ahorro energético, marleyvanegas@mail.uniatlantico.edu.co,0rcid:0000-0002-0513-7554,Universidad del Atlántico, Barranquilla, Colombia.

${ }^{2}$ Magister en Administración de empresas, danilohernandez@mail.uniatlantico.edu.co, Orcid: 0000-0001-7948-1764, Universidad del Atlántico, Barranquilla, Colombia.

${ }^{3}$ Doctor en Tecnología, diversificación, calidad y ahorro energético, evillicana@utec.edu.pe, Orcid: 0000-0000-0000-0000, Universidad de Ingeniería y Tecnología, Lima, Perú.

How to cite: M. Vanegas-Chamorro, D. Hernández, E. Villicaña-Ortiz, "Solar potential evaluation and political, economic and social analysis (PES) in the department Cesar-Colombia".. Respuestas, vol. 25, no. 2, pp. 62-72, 2020.

Received on February 07, 2020; Approved on April 5, 2020

\begin{tabular}{ll}
\hline ABSTRACT \\
\hline Keywords: & $\begin{array}{l}\text { This research shows the estimation of direct, diffuse and total irradiation in the department of Cesar } \\
\text { (Colombia) through the use of the Bird and Hulstrom model and parameterizations of the Mächler and Iqbal } \\
\text { model. The data used for this purpose were collected by the meteorological stations installed by the Institute } \\
\text { of Hydrology, Meteorology and Environmental Studies of Colombia (IDEAM) corresponding to the range } \\
\text { of collection and analysis with more than } 20 \text { years between } 1993 \text { and } 2013 \text {, a period of study suitable for a } \\
\text { Solar Irradiation, } \\
\text { Solarimetric Information, } \\
\text { Turbidity Coefficient, } \\
\text { Bird and Hulstrom Model, } \\
\text { Transmittance, }\end{array} \quad \begin{array}{l}\text { scenarios that depended on the type of atmosphere present in the study area. It was found that the solar } \\
\text { potential of the department of Cesar, located on the Colombian Caribbean Coast, presents average total } \\
\text { PES analysis. }\end{array}$ \\
$\begin{array}{l}\text { atmospheres, making it one of the regions with the highest irradiation values in Colombia. This panorama } \\
\text { allows to visualize the great potential that exists in the region for the implementation of projects with both } \\
\text { thermal and photovoltaic solar technologies. This study was also complemented with a political, economic } \\
\text { and social analysis of Colombia compared to the United State to determine the improvement opportunities } \\
\text { in Colombia. }\end{array}$
\end{tabular}

\section{RESUMEN}

\section{Palabras clave:}

Irradiación Solar, Información Solarimétrica, Coeficiente de turbidez, Modelo de Bird y

Hulstrom, Transmitancia, Análisis PES.
Esta investigación presenta la estimación de la irradiación directa, difusa y total del departamento del Cesar (Colombia) a través del uso del modelo de Bird y Hulstrom y parametrizaciones del modelo de Mächler e Iqbal. Los datos empleados para tal fin fueron recopilados por las estaciones meteorológicas instaladas por el Instituto de Hidrología, Meteorología y Estudios Ambientales de Colombia (IDEAM) y corresponden a un rango de recopilación y análisis de más de 20 años comprendido entre 1993 y 2013, periodo de estudio adecuado para un estudio solarimétrico exhaustivo. Se estimaron los datos de irradiación teniendo en cuenta cuatro tipos de escenarios climáticos que dependieron del tipo de atmósfera presente en la zona de estudio. Se encontró que el potencial solar del departamento del Cesar ubicado en la Costa Caribe colombiana, presenta promedios de irradiaciones totales que van desde $6.2 \mathrm{kWh} / \mathrm{m} 2$ día en atmósferas muy turbias hasta $6.8 \mathrm{kWh} / \mathrm{m} 2$ día en atmósferas extremadamente limpias, constituyéndose en una de las regiones con mayores valores de irradiación en Colombia. Este panorama permite visualizar el gran potencial existente en la región para la implementación de proyectos con tecnologías solares tanto térmica como fotovoltaica. Este estudio ademas fue complementado con un análisis politico, economico y social de Colombia y Estados Unidos para determinar las oportunidades de mejora en Colombia.

*Corresponding author.

E-mail Address:marleyvanegas@mail.uniatlantico.edu.co (Marley Vanegas Chamorro) 


\section{Introduction}

The novel challenges that Colombia is facing have forced different sectors of the economy to seek alternatives, and guarantee the energy supply security in the short and medium term protecting the environment. In this regard, the Colombian government approved Law 1715 in May 2014, whose objective is to promote the development and use of non-conventional energy sources (NCES) [1]. The approval of this law seeks to integrate the NCES, especially solar energy into the national energy system, thus creating the need to carry out a solarimetric study in the department of Cesar (Northern coast of Colombia), in order to evaluate the resource available in the region. For this reason, it is required to know the values of solar irradiation that reaches the surface of the earth.

The Sun emits energy that travels from its core and is distributed in an isotropic way throughout the universe. During this journey, solar radiation reaches the upper layers of the Earth's atmosphere and continues its path until it reaches the surface. In this path, the radiation is subjected to the attenuation process given by three phenomena: dispersion, reflection and absorption [2]. These processes take place when radiation collides with particles and molecules suspended in the atmosphere such as water vapour, miscible gases, air molecules, ozone and aerosols. The presence of these particles depends mainly on the physical, climatic and meteorological characteristics of the place under study[3][4][5].

The solar energy quantification may be developed by means of different methods, either through the use of measurement instruments, satellite image processing, or with the application of physical models. The above is interesting for those places that have climate information and where access to specific measurement instruments (pyranometers, pyrheliometers, etc.) or access to satellite information is restricted due to their high costs. If the end use is of an energy type, the availability of the resource will have to be determined more precisely, so a radiation study that considers the type of atmosphere (clear or covered skies) will be essential. If the end-use is non-energy, it will be sufficient to establish the average radiation value, without the need to include a detailed analysis of the atmospheric conditions. Therefore, in order to carry out this analysis, the magnitude of the attenuating effects of dispersion and absorption, which are a function of optical depth and the concentration and quantity of substances present in the atmosphere, must be determined [6].

For all of the above, a specific study was conducted where different variables were analyzed that allowed the availability of the solar resource in the department of Cesar to be evaluated based on the analysis of meteorological data from 12 stations located in the study region with 20-year climate records and evaluated through the Bird Hulstrom model and parameterizations of the Mächler and Iqbal model [7], which contemplates the calculation of incident irradiation on earth taking into account different types of atmosphere [8][9][10][11].

\section{Materials and methods}

\section{The origin of the data}

The weather stations are distributed throughout the department of Cesar, this department is located at the coordinates $10^{\circ} 29^{\prime} 00^{\prime \prime} \mathrm{N}$ and $73^{\circ} 15^{\prime} 00^{\prime \prime} \mathrm{O}$. The types of instruments used to measure the meteorological variables analyzed in this study are listed below: Pressure sensor Lambrecht Ref. 8121, temperature sensor Siap + Micros Ref. T001-TTEP-N and relative humidity Siap + Micros Ref. T003-TEH-V.

\section{Solar radiation model by atmospheric transmissibility}

For the calculation of total, direct and diffuse irradiation in the department of Cesar (Colombia), the Bird \& Hulstrom model was used, which employs parameters and variables of a geographical, astronomical, geometric, physical and meteorological nature of the place being studied [6]. Historical data collected during 20 years from the stations installed in the department of Cesar and administered by IDEAM were used. Other atmospheric parameters published by this institute in the Atlas of Solar Radiation of Colombia were also used. All this information was organized through a computer tool developed for this purpose, obtaining a set of data of relevant importance for this study. Through this model, the coefficients of atmospheric transmissibility were calculated, which allowed the calculation of the direct irradiation (IDH) and diffuse irradiation (IdH), which allows knowing the value of the total irradiation (ITH).

The direct radiation on the horizontal surface is 
determined from equation (1), which considers different atmospheric turbidity indices, a value also known by atmospheric transmittance (prom) [6]. Table 1 lists the parameters for calculating this value.

$$
I_{D H}=\left[0,9662\left(C_{r}\right)\left(\tau_{\text {prom }}\right)\right] \operatorname{Sen} A \quad(\mathrm{~W} / \mathrm{m} 2)
$$

Where: $\mathrm{Cr}$ corresponds to the daily solar constant that is a function of the Julian day measured in W/m2, 0.9662 is the correction factor that adjusts to the wavelength interval where $96 \%$ of the radiation is concentrated and $\mathrm{A}$ is the solar altitude angle.

Table 1. Parameters of atmospheric transmittance

\begin{tabular}{cl}
\hline Symbol & \multicolumn{1}{c}{ Transmittance } \\
\hline$\tau_{\mathbf{r}}$ & Transmittance by scattering due to air molecules. \\
$\tau_{\mathbf{0}}$ & Transmittance due to absorption of ozone. \\
$\tau_{\mathbf{g}}$ & Transmittance due to absorption by the uniform gases mixture \\
$\tau_{\mathbf{w}}$ & Transmittance due to absorption of water vapor \\
$\tau_{\mathbf{a}}$ & Transmittance due to absorption and scattering by the presence of aerosols. \\
\hline & \multicolumn{1}{c}{ Source: Valencia, G., Vanegas, M. y Villicaña, E. }
\end{tabular}

For the calculation of each of these transmittance values, different parameters were taken into account, which are listed in Table 2.

Table 2. Atmospheric transmittance dispersion parameters

\begin{tabular}{ccc}
\hline Transmittance & $\begin{array}{c}\text { Transmission } \\
\text { coefficient }\end{array}$ & Parameters \\
\hline$\tau_{\mathrm{r}}$ & Air molecules & Optical air mass $\left(m_{a}\right)$ \\
$\tau_{\mathrm{o}}$ & Uniform gases mixture & Optical air mass $\left(m_{a}\right)$ \\
$\tau_{\mathrm{g}}$ & Ozone & Thickness of the ozone layer \\
$\tau_{\mathrm{w}}$ & Water & Amount of precipitable water \\
$\tau_{\mathrm{a}}$ & Aerosols & Turbidity of the atmosphere $(\beta)$ \\
\hline
\end{tabular}

Source: own elaboration

For transmittance due to the presence of aerosols, the parameterization carried out by Mächler is used, which is represented in Iqbal's model [12][13]. This transmissibility is obtained by equation 2 .

$$
\tau_{a}=0,12445 \alpha-0,0162+(1,003-0,125 \alpha) \cdot e^{-\beta m_{a}^{(1.089 \alpha+0,5123)}}
$$

In this expression the turbidity coefficient $(\beta)$ is introduced [5], in which parameters such as average particle size $(\alpha)$, aerosol density $(\beta)$ and air mass ma are considered. For this analysis it is established that the mean value of a particle is $1.3 \mu \mathrm{m} \pm 0.2$, thus coinciding with other studies [4][14] considers that, for the density of aerosols this value can vary from 0.0 for an extremely clean atmosphere, to 0.4 as the maximum limit for an atmosphere with very high turbidity. In this study, $\beta$ takes the value from 0.0 to 0.4 , which represents five types of atmosphere: 0.0 is equivalent to an extremely clean atmosphere, 0.1 is equivalent to a clear atmosphere, 0.2 is equivalent to a medium atmosphere, 0.3 is considered to be a turbid atmosphere and 0.4 a very turbid atmosphere.

In this model, the value of the transmittance by scattering (r) is in charge of verifying the change of direction suffered by the solar radiation due to the presence of air molecules. This is allowed thanks to equation (3).

$$
\tau_{r}=e^{-0,0903 \cdot m_{a}^{0,84}\left(1+m_{a}-m_{a}^{1,01}\right)}
$$

The optical air mass (ma) is defined in equation (4). 


$$
m_{a}=\frac{P_{T} * m_{r e l}}{101325}
$$

Equation (5) is designed to calculate PT which is the total air pressure measured in $(\mathrm{Pa})$, which is a function of altitude (z) [15].

$$
P_{T}=101325 e^{-0.0001184^{*} z}
$$

To calculate the mass air value is necessary to define the relative air mass (mrel) determined from the Equation (6). In this equation $U$ is the zenithal angle calculated in function of the earth's curvature.

$$
m_{\text {rel }}=\frac{1}{\cos U+0,15 \cdot[93,885(U)]^{-1,253}}
$$

The model considers the contribution of three solar components for the diffuse irradiance calculation, as follows:

$I d r$ : due to the existence of air molecules.

Ida: due to the existence of dust particles.

$I d m$ : due to the multiple reflection between the ground and the atmosphere.

Equation (7) is applied in the model to calculate diffuse radiance considering air particles, as follows:

$$
I_{d r}=\left[0,79\left(\tau_{o} \tau_{g} \tau_{w} \tau_{a a}\right)(0,5)\right]\left[\frac{\left(1-\tau_{r)}\right.}{\left(1-m_{a}+m_{a}^{1,02}\right)}\right] \operatorname{Sen} A \quad\left(\mathrm{~W} / \mathrm{m}^{2}\right)
$$

where $\tau_{\mathrm{aa}}$ is the transmittance due to the aerosol absorption in function of the albedo generated by the air particles dispersion, air mass, and the aerosol transmittance. The Equation 7 defines SenA like the incidence angle respect to the horizontal plane (solar altitude). This numerical data may be calculated by a trigonometric function which requires a solar declination, as shows in Equation 8.

$$
\operatorname{Sen} A=\cos \delta \cdot \cos \lambda \cdot \cos H s+\operatorname{sen} \delta \cdot \operatorname{sen} \lambda
$$

where $\delta$ is solar declination, $\delta$ is latitude of the region, and Hs is the solar hour. On the other hand, Ozone molecule dispersion transmittance is calculated by the Equation 9 .

$$
\begin{aligned}
& \tau_{o}=1-\left[0,1611\left[\left[\left(L_{0} \cdot m_{r e l}\right)\left(1+139,48 \cdot L_{o} \cdot m_{r e l}\right)^{-0,3035}\right]+\right.\right. \\
& \left.\left.\frac{0,002715 \cdot L_{0} \cdot m_{r e l}}{1+0,044 \cdot U_{3}+0,003\left(L_{o} \cdot m_{r e l}\right)^{2}}\right]\right]
\end{aligned}
$$

where $L o$ refers to the thickness of the ozone layer. This numerical value was taken from the Solar Atlas of Colombia [16]. The transmittance due to water vapor is obtained from equation 10, where it is required to calculate the amount of precipitable water measured in $\mathrm{cm}(W W)$ in the vertical of the site.

$$
\tau_{w}=1-\frac{2,4959 \cdot\left(W W \cdot m_{r e l}\right)}{\left(1+79,034 \cdot W W \cdot m_{r e l}\right)^{0,6828}+\left(6,385 \cdot W W \cdot m_{r e l}\right.}
$$

Equation 11 is used to calculate the transmittance due to the presence of gases such as $\mathrm{CO} 2$ and $\mathrm{O} 2$ known as uniformly miscible gases, in which the solar absorption radiation cover importance since $\mathrm{CO} 2$ absorbs long wave radiation (infrared), and $\mathrm{O} 2$ absorbs short wave radiation (ultraviolet).

$$
\tau_{g}=e^{-0,0127 m_{a}^{0,26}}
$$

The diffuse radiation due to the presence of aerosols, represented by Equation (12), is calculated from Iqbal's Model C, which is a function of the percentage of energy that approaches the earth's surface due to aerosol dispersion $(\mathrm{Fc})$. In this case, its value can be estimated from the parameterization made by Mac, whose calculation is a function of the atmospheric mass (ma) [11][13].

$$
I_{d a}=\left[0,79\left(C_{r}\right)\left(\tau_{o} \tau_{g} \tau_{w} \tau_{a a}\right)\left(F_{c}\right)\right]\left[\frac{\left(1-\tau_{a s}\right)}{\left(1-m_{a}+m_{a}^{1,02}\right)}\right] \operatorname{Sen} A_{(12)}
$$

In this equation, the transmittance $\left(\tau_{a s}\right)$ that is due to aerosol diffusion is used like a function of $\left(\tau_{a}\right)$ and $\left(\tau_{a a}\right)$. Diffuse irradiance calculation requires the surface reflection coefficients $\left(p_{g}\right)$ generally tabulated, and evaluate the atmospheric albedo. That is, the multiple reflection between the ground and the $\left(p_{a}\right)$, and the transmittance due to the aerosol diffusion [13]. As shown in the Equation 13. 


$$
I_{d m}=\left[I_{D H} \operatorname{sen} A+I_{d r}+I_{d a}\right]\left[\frac{\left(\rho_{g} \cdot \rho_{a}^{\prime}\right)}{\left(1-\rho_{g} \cdot \rho_{a}^{\prime}\right)}\right]\left(\mathrm{W} / \mathrm{m}^{2}\right)
$$

As mentioned in principle, this model indicates an equivalence between the sum of direct and diffuse irradiation as presented in Equation (14).

$$
I T H=I D H+I D H
$$

\section{PES Analysis}

In this section is presented a comparative policy, economic and social analysis of Colombia and United States, which allowed to identify a new strategy to promote this renewable energy in Colombia.

The United States has made great progress in the field of research and generation of solar energy, and is currently the country with the greatest increase in its installed capacity over the previous year, breaking the record it set two years ago. In the economic field, the country has a great investment support from both the state and private investors interested in the growth of solar energy generation. The most unfavorable aspect is the political environment that threatens to negatively affect the development and evolution of renewable energy sources in the country, all due to the withdrawal of the president of the United States, Donald Trump, from the Paris agreement in 2017 [17].

China is behind the United States as the country that has obtained the greatest technological and economic increase in recent years thanks to large investments at the end of 2014; in total, the PEST analysis is extremely favorable for this country, which has made its inhabitants, investors and leaders aware of the importance of mitigating contaminating emissions in the short term [18].

In Colombia the situation is more unfavorable because the country does not currently have the help of external factors that allow its technological development. The production costs and prices of solar photovoltaic technology have decreased considerably in the last ten years, which is considered a very favorable aspect for the development of this technology, but the government has not been working on this issue for many years. Currently, meetings and conventions are being held at the Ministry of Mines and Energy to study this latent fact [19].

The PES analysis of solar energy in the United States and

Table 3. PES analysis of solar energy in the United States and Colombia 


\begin{tabular}{|c|c|c|}
\hline Criteria & United Sates & Colombia \\
\hline Policies & $\begin{array}{l}\text { In } 2017 \text {, Trump has taken steps to ease } \\
\text { the burden on the coal-producing } \\
\text { country by breaking environmental } \\
\text { standards and committing to } \\
\text { withdrawing the United States from the } \\
\text { Paris climate agreement. While the U.S. } \\
\text { does not have a national energy policy, } \\
\text { many states have set individual } \\
\text { renewable energy targets with solar } \\
\text { energy included in various proportions. }\end{array}$ & $\begin{array}{l}\text { The ICONTEC has issued } \\
\text { regulations on photovoltaic energy } \\
\text { that are very useful for companies } \\
\text { that import, produce and install solar } \\
\text { energy systems, based on Law } 1715 \\
\text { of } 2014 \text {. There are } 23 \text { NTC for } \\
\text { thermal or energy use of solar } \\
\text { systems, some specifying terms, } \\
\text { optimal usability tests, } \\
\text { implementation guidelines in rural } \\
\text { and urban areas, among others. }\end{array}$ \\
\hline Economic & $\begin{array}{l}\text { Over the period } 2004-2007 \text {, total } \\
\text { investment in the US solar industry } \\
\text { increased by a } 145 \% \text { compound annual } \\
\text { growth rate (CAGR), from } \$ 215 \\
\text { million to almost } \$ 3.2 \text { billion. Today, } \\
\text { solar energy is more affordable, } \\
\text { accessible and prevalent in the United } \\
\text { States than ever before. Since } 2008 \text {, } \\
\text { U.S. installations have increased } \\
\text { seventeen-fold, from } 1.2 \text { gigawatts } \\
\text { (GW) to about } 30 \mathrm{GW} \text { today. Since } \\
2010 \text {, the average cost of solar } \\
\text { photovoltaic panels has been reduced } \\
\text { by more than } 60 \% \text { and the cost of a } \\
\text { solar electric system has been reduced } \\
\text { by } 50 \% \text {. }\end{array}$ & $\begin{array}{l}\text { In } 2018 \text {, construction is expected to } \\
\text { begin on one of the most ambitious } \\
\text { renewable energy projects in } \\
\text { Colombia today. It is a complex of } \\
\text { solar panels that the company ENEL } \\
\text { is starting to build in E1 Paso, Cesar. } \\
\text { The company has invested about } \\
\text { US } \$ 70 \text { million ( } \$ 210.7 \text { billion) to } \\
\text { build } 250,000 \text { solar panels that will } \\
\text { make up the entire energy complex. }\end{array}$ \\
\hline Social & $\begin{array}{l}\text { The solar industry is a proven incubator } \\
\text { for employment growth throughout the } \\
\text { country. Solar jobs have increased by } \\
\text { about } 123 \% \text { since November } 2010 \text {, } \\
\text { with nearly } 209,000 \text { solar workers in } \\
\text { the United States. According to a } \\
\text { University of California report } \\
\text { published in also states that solar } \\
\text { photovoltaic energy per megawatt } \\
\text { creates more jobs than other energy } \\
\text { technologies. For every megawatt } \\
\text { installed, about } 20 \text { manufacturing and } \\
13 \text { installation/manufacturing jobs are } \\
\text { created. }\end{array}$ & $\begin{array}{l}\text { Waste from the mining industry is } \\
\text { being reused in the department of } \\
\text { Antioquia to produce solar panels } \\
\text { that are now being used in eleven } \\
\text { educational institutions in the } \\
\text { region. The project manager } \\
\text { explains that these solar panels are } \\
\text { now being used to meet essential } \\
\text { needs such as running school } \\
\text { kitchens or computers in } \\
\text { classrooms. }\end{array}$ \\
\hline
\end{tabular}

\section{Results and Discussion}

Figure 1 shows the geographical location of the weather stations distributed throughout the department of Cesar. A total of 12 stations were selected to measure meteorological variables such as temperature, relative humidity, pressure, wind speed and direction, among other variables. This department presents stations used to measure solar radiation such as the stations of Fedearroz, San Martin-Aguachica and the station of Valledupar. Table 4 lists the meteorological stations included in this study; there may be other stations located in this area, but they were not selected because the data stored by them have few years of measurements or discontinuity was found in the information stored.

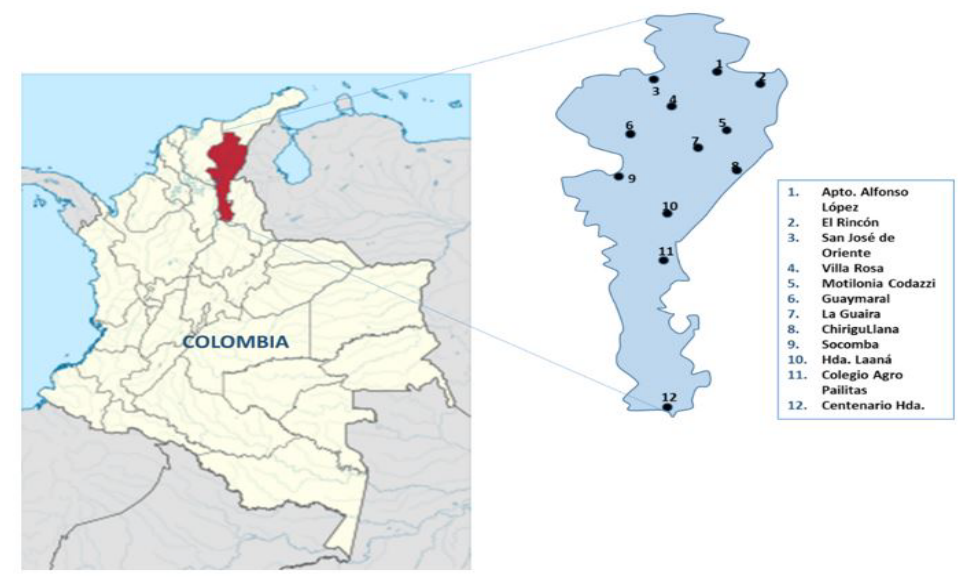

Figure 1.- Location of weather stations at Cesar (Colombia). Source: [16].

Historical temperature and relative humidity series were taken on a daily basis, recorded in the morning, at midday 
and in the afternoon during the period 1983-2013. The processing of the information was complemented by a mathematical-statistical treatment in the different time series, periods or laps, through the elaboration of a code in the computer tool Matlab ${ }^{\circledR}$, which was programmed to speed up the processing of the information.

The data listed in Table 4 shown that the department relief is characterized by moderate elevations which influence the temperature and relative humidity predominant in the region. This characteristic of the relief allows finding areas with elevations of up to 850 meters above sea level where the average temperature is $24.9^{\circ} \mathrm{C}$ and the relative humidity is $79.5 \%$. There are also areas at lower altitudes ( 40 meters above sea level) where the average temperature is $26.8^{\circ} \mathrm{C}$ and the average relative humidity is $74.3 \%$.

Table 4. Data from stations located at the department of Cesar.

\begin{tabular}{ccccccc}
\hline Region & Station & $\begin{array}{c}\text { Latitude } \\
\left({ }^{\circ} \mathbf{N}\right)\end{array}$ & $\begin{array}{c}\text { Length } \\
\left({ }^{\circ} \mathbf{O}\right)\end{array}$ & $\begin{array}{c}\text { Elevation } \\
(\mathbf{m s n m})\end{array}$ & $\begin{array}{c}\text { Temperature } \\
\left({ }^{\circ} \mathbf{C}\right)\end{array}$ & $\begin{array}{c}\text { HR } \\
(\mathbf{\%})\end{array}$ \\
\hline \multirow{4}{*}{ Chiriguaná } & 9.21 & 73.35 & 40 & 26.79 & 74.33 \\
& Guaymaral & 9.54 & 73.38 & 50 & 28.46 & 60.55 \\
& Hda. La Guaira & 9.37 & 73.48 & 50 & 28.54 & 76.10 \\
& Col Agro Pailitas & 8.57 & 73.38 & 50 & 25.22 & 71.74 \\
& Villa Rosa & 10.11 & 73.32 & 70 & 27.84 & 66.44 \\
& Centenario Hda & 9.51 & 73.16 & 100 & 28.11 & 76.37 \\
& La Llana & 7.04 & 73.32 & 120 & 27.35 & 85.39 \\
& Apto Alfonso López & 10.26 & 73.14 & 138 & 19.37 & 60.03 \\
& Socomba & 9.41 & 73.14 & 170 & 27.91 & 76.02 \\
& Motilonia Codazzi & 10.00 & 73.15 & 180 & 27.57 & 69.03 \\
& El Rincón & 10.16 & 73.07 & 350 & 26.34 & 76.53 \\
& San José de Oriente & 10.21 & 73.32 & 850 & 24.89 & 79.51 \\
\hline
\end{tabular}

Figure 2 shows the trend followed by these three variables which have an appreciable influence on the irradiation behavior. Elevation influences both temperature and humidity, these values are the main variables required by the Bird and Hulstrom model to calculate irradiation.

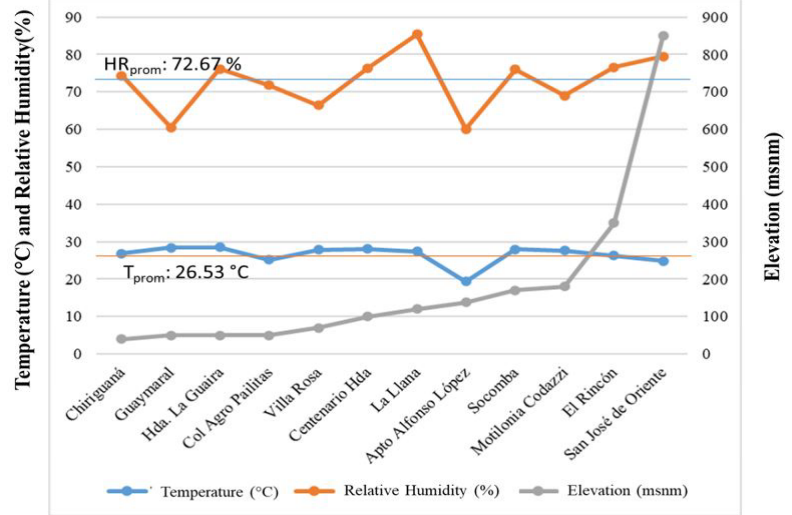

Figure 2. Average temperature and relative humidity profiles characteristic of the region under study. Source: Own elaboration

Figures $3 \mathrm{a}, \mathrm{b}$ and $\mathrm{c}$ show the values of total, direct and diffuse irradiation predominant at department of Cesar during 
the months of the year. Each irradiation was calculated taking into account different types of atmospheres, where the turbidity coefficient $(\beta)$ varied from 0.0 for extremely clean atmosphere to 0.4 for turbid atmosphere.

The total irradiation is higher during the first months of the year, reaching values higher than $8 \mathrm{kWh} / \mathrm{m} 2 \mathrm{day}$ (February) considering an extremely clean atmosphere $(\beta=0.0)$. If we consider a turbid atmosphere $(\beta=0.4)$, the total irradiation value falls to $7.3 \mathrm{kWh} / \mathrm{m} 2 \mathrm{day}$, this is an adequate response due to the atmosphere contains more gases and vapours that prevent the radiation arrives from the horizontal surface.

The bimodal behavior along the year produces fluctuations in the total irradiance with minimum values during the months of may and october. Values of 6.1 and $5.8 \mathrm{kWh} / \mathrm{m} 2$ day respectively are observed taking into account an extremely clean atmosphere, for a turbid atmosphere, these months presented values of 5.5 and $5.3 \mathrm{kWh} / \mathrm{m} 2$ day, respectively. October is the rainiest month in the department of Cesar, with an average rainfall of $223 \mathrm{~mm}$ as reported in the Climate-data.org database. Therefore, there is a lot of cloudiness in this season which attenuates the radiation, therefore, october presents one of the lowest values for the total irradiation.

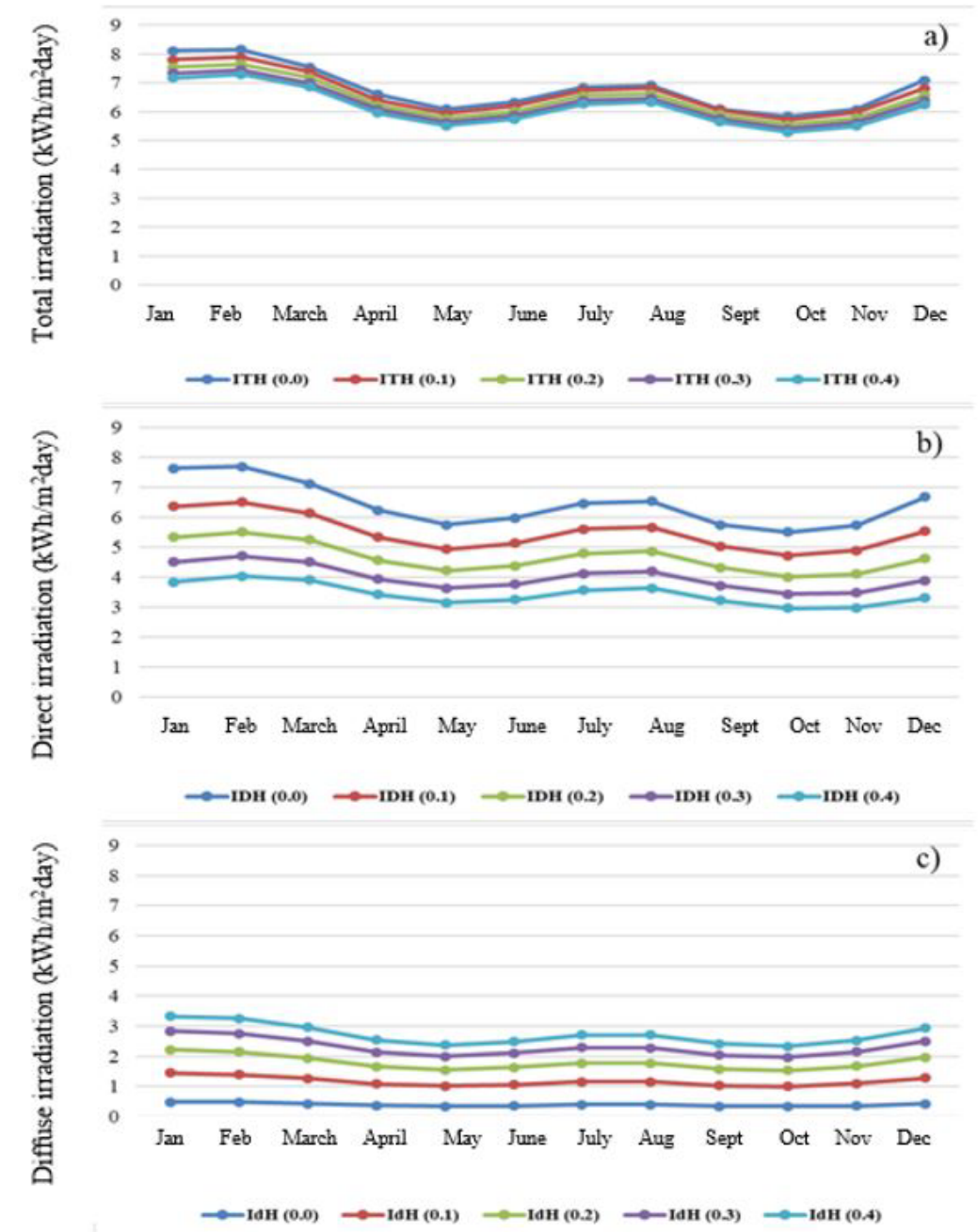

Figura 3. Total, direct and diffuse irradiation taking into account the variation in the turbidity coefficient $\beta(0,0), \beta(0,1), \beta(0,2), \beta(0,3)$ y $\beta(0,4)$.

Source: Own elaboration

Figure 3c shows the behavior of diffuse irradiation, whose values, considering an extremely clean atmosphere, are the lowest because to the low variation throughout the year as expected. However, highest values are presented 
considering a very turbid atmosphere, especially in the months of January and February. The contribution of direct and diffuse radiation presents a great importance in the decision-making process that leads the implementation of solar, thermal and photovoltaic energy projects. Both components are considered, but a higher percentage of direct irradiation is a relevant aspect when implementing photovoltaic solar energy projects.

On the other hand, the rainfall influence throughout the year affects the irradiation behavior, as shown in Figure 4. This figure presents the trends which follows the total irradiation calculated through the Bird and Hulstrom model compared with the rainfall developed throughout the year.

May and October are the months with the highest precipitation values, especially in October, therefore, its irradiation is the lowest in the year. This is due to the presence of water vapor; water molecules absorb the most radiation. Their degree of absorption depends on the optical mass of the water vapor or the thickness of precipitable water, this amount is a function of temperature the relative humidity of the place [6].

Although Bird and Husltrom's model is rigorous, it does not take into account the influence of wind, according to the Figure 4. December, January and February months present the highest total irradiation values, this phenomenon is associated to the maximum wind speeds registered in this region of the country for these months. Therefore, the irradiation values estimated by the model may be a little higher for this time of the year.

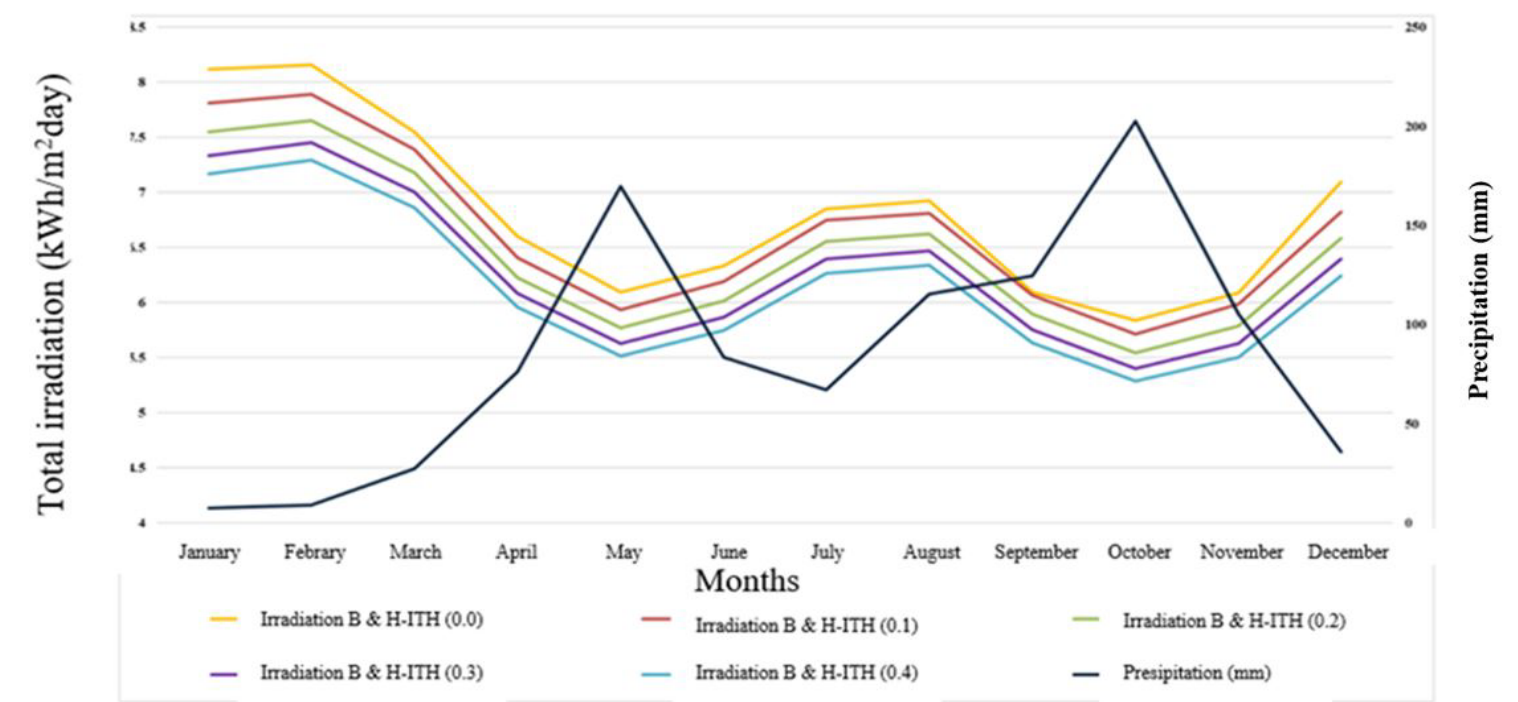

Figure 4. Total irradiation calculed through Bird and Hulstrom model against irradiation experimentally measured at Valledupar station (Department of Cesar). Source: Own elaboration.

In general terms, for the development of isolated photovoltaic solar installations, a level of irradiation between 3.0

and $4.0 \mathrm{kWh} / \mathrm{m} 2$ day is required. In the case of solar installations with a grid connection, in addition to hours of sunshine, and places free of shadows, a level of irradiation greater than $4.0 \mathrm{kWh} / \mathrm{m} 2$ day is required. In areas where diffuse irradiation is predominant, it is not advisable to carry out photovoltaic installations, as the energy transformation has a low yield. For this reason, locations with significant cloudiness throughout the year are not suitable for the development of solar photovoltaic installations with grid connection.
Lower levels of daily solar irradiation are required for low temperature thermal concentration (LTC) systems around 2.5 and $3.0 \mathrm{kWh} / \mathrm{m} 2$ day. However, direct radiation is required in the medium and high temperature (CSP) of thermal systems, because the temperature applied must be higher than $400^{\circ} \mathrm{C}$ with this technology. The most suitable locations must have many hours of direct sunshine, at least $2000 \mathrm{kWh} / \mathrm{m} 2$ of solar radiation per square meter every year [20].

According to what has been described above, the department of Cesar presents interesting levels of 
irradiation for the development of solar installations of different types, although when considering a cloudy atmosphere, the results obtained indicate that technologies such as CSP (Concentrated Solar Power) are not profitable in some areas due to the percentage of cloudiness that can occur throughout the year. However, this region offers possibilities for the development of photovoltaic installations, either for connection to the grid or as isolated installations. For grid connection systems, the areas with the greatest potential are those located in the center and north of the department of Cesar.

\section{Conclusions}

From the results obtained in this research, it is important to emphasize that, for the area studied, the use of mathematical models allows the obtaining of solarimetric information with a high degree of reliability, in addition it does not suppose a high cost. The data provided by IDEAM allowed the application of the model for the calculation of radiation parameters whose results offer a clear opportunity for the exploration and recognition of the areas with the greatest potential for the implementation of solar technologies.

When comparing the estimated radiation data through the Bird and Hulstrom model and the measured values of this variable through instruments available at the Valledupar weather station, differences in the measurements are observed, which are more marked in the months of December, January and February, a time when wind speeds are considerably higher than at other times of the year. This could be attributed to the fact that the model used in this research does not take into account parameters related to the wind part, which is why it is recommended to analyze in more detail the rigor of the model.

The availability of the solar resource depends on the climatic characteristics of each area, so the climatic and meteorological factors condition the degree of attenuation that the solar radiation can have and, therefore, the amount of usable resource.

It was found that the department of Cesar has an excellent potential for the development of solar technologies both thermal (low and medium temperature) and photovoltaic. The values obtained indicate that in the months of January and February there are maximum values of solar irradiation, while in May and October the lowest values are observed, this due to the presence of rain, however, these values are adequate for the implementation of solar photovoltaic and low temperature thermal systems.

\section{References}

[1] C. de la república Diario Oficial, "Ley 1715 de 2014 de la República de Colombia," 2020. file:///C:/Users/User/Downloads/Leyes desde 1992 - Vigencia expresa y control de constitucionalidad [LEY_1715_2014].pdf.

[2] J. Bosca, "Contribucion al estudio de la radiacion solar y de la determinacion de la turbiedad atmosferica. Aplicacion a Valencia y Sevilla.," Universitat Politècnica de València, 1995.

[3] A. Q. Malik, "A modified method of estimating Ångström's turbidity coefficient for solar radiation models," Renew. Energy, vol. 21, no. 3, pp. 537-552, 2000, doi: https://doi.org/10.1016/ S0960-1481(00)00080-X.

[4] J. Cañada, J. Pinazo, and J. Bosca, "Determination of Angstrom 's turbidity coefficient at Valencia," Renew. Energy, vol. 3, no. 6-7, pp. 621-626, 1993, doi: 10.1016/0960-1481(93)90068-R.

[5] A. Angstrom, "Determinig the Turbidity of the Atmosphere'," Tellus XIII, 1961, [Online]. Available: https://onlinelibrary.wiley.com/doi/ pdf/10.1111/j.2153-3490.1961.tb00078.x.

[6] E. Villicaña, "Método de evaluación de la radiación solar por transmisibilidad atmosférica. Aplicación a la determinación del potencial energético solar de México," Universidad de Oviedo, 2012.

[7] M. Mächler, "Parameterization of solar irradiation under clear skies," The University of British Columbia, 1983.

[8] R. E. Bird and R. Hulstrom, "A simplified clear sky model for direct and diffuse insolation on 
horizontal surfaces," Sol. Energy Res. Inst., 1981, [Online]. Available: https://www.nrel.gov/ docs/legosti/old/761.pdf.

[9] M. V. Chamorro and L. A. Viana, "Cuantificación y caracterización de la radiación solar en el departamento de La Guajira-Colombia mediante el cálculo de transmisibilidad atmosférica Quantification and characterization of solar radiation at the department of $\mathrm{La}$ Guajira-Colombia by calculating atmospheric transmissivity," 2015.

[10] A. J. Guti, P. Paredes-s, E. Villica, and J. Xiberta-bernat, "Solar energy potential in the coastal zone of the Gulf of Mexico," vol. 81, pp. 534-542, 2015, doi: 10.1016/j. renene.2015.03.068.

[11] A. J. Gutiérrez-trashorras, E. Villicañaortiz, E. Álvarez-álvarez, J. M. Gonzálezcaballín, J. Xiberta-bernat, and M. J. Suarezlópez, "Attenuation processes of solar radiation . Application to the quanti fi cation of direct and di ff use solar irradiances on horizontal surfaces in Mexico by means of an overall atmospheric transmittance," Renew. Sustain. Energy Rev., vol. 81, no. July 2017, pp. 93-106, 2018, doi: 10.1016/j.rser.2017.07.042.

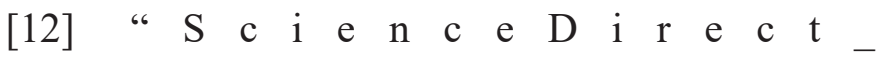
articles_11Aug2020_05-40-54.”.

[13] M. Iqbal, "Correlation of average diffuse and beam radiation with hours of bright sunshine," Sol. Energy, vol. 23, no. 2, pp. 169-173, 1979, doi: https://doi.org/10.1016/0038-092X(79)90118-X.

[14] M. Iqbal, An Introduction to Solar Radiation. 1983.

[15] O. Pizano, Manual de climatización, Tomo II. España: Universidad Politécnica de Valencia, 1995.
[16] IDEAM, "Atlas de Radiación Solar, Ultravioleta y Ozono de Colombia," 2015. http:// atlas.ideam.gov.co/visorAtlasRadiacion.html.

[17] Q. Wang, S. Li, and Z. Pisarenko, "Heterogeneous effects of energy efficiency, oil price, environmental pressure, R\&D investment, and policy on renewable energy -- evidence from the G20 countries," Energy, vol. 209, p. 118322, 2020, doi: https://doi.org/10.1016/j. energy.2020.118322.

[18] Z. Chen, J. Dong, and R. Ren, "Urban underground logistics system in China: Opportunities or challenges?," Undergr. Sp., vol. 2, no. 3, pp. 195-208, 2017, doi: https://doi. org/10.1016/j.undsp.2017.08.002.

[19] M. F. Zabaloy, M. Y. Recalde, and C. Guzowski, "Are energy efficiency policies for household context dependent? A comparative study of Brazil, Chile, Colombia and Uruguay," Energy Res. Soc. Sci., vol. 52, pp. 41-54, 2019, doi: https://doi.org/10.1016/j.erss.2019.01.015.

[20] C. Richter, S. Teske, and R. Short, Energía Solar Térmica de Concentración. Perspectiva mundial 2009. Greenpeace Internacional, SolarPACES, ESTELA, 2009. 